\title{
20. Yüzyıl Genişletilmiş Keman Çalma Tekniklerinin Eğitimde Kullanım Durumunun İncelenmesi
}

\author{
Examination of the Use of $\mathbf{2 0}^{\text {th }}$ Century Extended Violin Playing \\ Techniques in Education
}

\author{
Nazlı Başak BAŞAK ${ }^{1}$ (I), Hakan BAĞCI² (D)
}

'Öğr.Gör., Kocaeli Üniversitesi, Güzel Sanatlar Fakültesi Müzik Bölümü, Kocaeli, Türkiye

${ }^{2}$ Doç.Dr., Kocaeli Üniversitesi, Güzel Sanatlar Fakültesi Müzik Bölümü, Kocaeli, Türkiye

ORCID: GN.B.B. 0000-0002-8999-283X; H.B. $0000-0001-5312-3168$

\section{Sorumlu yazar/Corresponding author: Nazlı Başak BAŞAK, \\ Kocaeli Üniversitesi, Güzel Sanatlar Fakültesi Müzik Bölümü, Anıtpark Yerleşkesi, İzmit Kocaeli, Türkiye \\ E-posta/E-mail: nazli.basak@kocaeli.edu.tr \\ Başvuru/Submitted: 19.03.2021 \\ İlk Revizyon/Revision Requested: 11.05.2021 Son Revizyon/Last Revision Requested: 31.05.2021 \\ Kabul/Accepted: 31.05 .2021 \\ Online Yayın/Published Online: 00.00 .0000}

Atıf/Citation: Basak, N.B., \& Bagci, H. (2021). 20. yüzyıl genişletilmiş keman çalma tekniklerinin eğitimde kullanım durumunun incelenmesi. Konservatoryum - Conservatorium, 8(1), 63-83. https://doi.org/10.26650/CONS2021-900016
ÖZ

Bu araştırmada, 20. yüzyıl genişletilmiş keman çalma tekniklerinin lisans düzeyinde eğitim veren konservatuvarlar, güzel sanatlar, eğitim, müzik ve sahne sanatları ve sanat ve tasarım fakültelerindeki eğitimde kullanım durumlarının tespit edilmesi amaçlanmıştır. Araştırmacının ulaşabildiği ulusal ve uluslararası kitap, hakemli dergi, lisansüstü tez çalışmaları gibi kaynaklar araştırılarak, literatürde yer alan genişletilmiş keman çalma teknikleri üzerine çalışmalar tespit edilmiş, çeşitliliği sağlamak amacıyla örnek olarak seçilen ve katılımcılar tarafından eklenen 60 teknik baz alınmıştır. Araştırma, tarama modeli bir araştırmadır. Araştırma evrenini keman eğitimcileri, örneklemi 30 keman eğitimcisi oluşturmaktadır. Örneklemde yer alan eğitimciler için 4'ü açık uçlu olan 10 anket sorusu geliştirilmiştir. Araştırma sonuçlarına göre; genişletilmiş keman çalma tekniklerinin keman eğitiminde sayıca kullanım durumu ve hangilerinin ne kadar kullanıldığı belirlenmiş, en çok 'Bartok pizzicato' ve 'sağ elle çekerek pizzicato', en az'malet kullanımı' ve 'cam çubukla tellere vurma' gibi tekniklerin kullanıldığı görülmüştür. Öğretimde kullanılan etütlerin/eserlerin sayıca 1 ile 5 arası olduğu, çoğunluğun bu tekniklerin öğretimine yönelik öğretici kitap kullanmadığı, tekniklerin çalgı derslerinde öğretilmesinin gerekli/faydalı olduğu, konu ile ilgili ayrı bir ders olarak ve uygulayarak gösterme/örnekleme yöntemleriyle öğretilmesi gerektiği, öğrenci profilinin yeterli bulunmadığı, öğrenme sürecine dahil olamadığı, genişletilmiş çalma tekniklerinin müfredatta bulunması gerektiği ve Türkiye'de yetişen keman eğitimcilerinin bilgi ve donanım durumunun yeterli bulunmadığı görülmüştür.

Anahtar Kelimeler: Keman tekniği, Keman eğitimi, 20. yüzyıl

\section{ABSTRACT}

This study aims to determine the use of 20th-century expanded violinplaying techniques in undergraduate-level conservatories; faculties of fine arts, education, music and performing arts, and arts and design. The study conducted a search in available national and international resources, such as books, refereed journals, and postgraduate theses, and scanned the literature for such techniques. The study used the survey model and identified 60 techniques. Furthermore, the study selected 30 violin instructors to respond to 
10 survey questions, four of which were open-ended. The search results indicated that a Bartok pizzicato and a right-hand touch pizzicato are the most common techniques, whereas a mallet and a glass stick used to strike the strings are the least common. The number of etudes/pieces used in teaching ranged between one and five. A majority of instructors do not use instructional books, necessary/useful in teaching the cited techniques in dedicated courses as part of instrument education through demonstration. The student profile is insufficient, indicating that students are not involved in the learning process. The study recommends that methods of teaching expanded techniques should be included in the curriculum to enhance the knowledge and preparedness of violin instructors educated in Turkey.

Keywords: Violin technique, Violin education, 20th Century

\section{EXTENDED ABSTRACT}

In Turkey, violin education in the field of classical western music at the undergraduate level is conducted in various institutions, such as conservatories; faculties of fine arts, education, music and performing arts, and arts and design, which offer occupational music education. The techniques used in this field are well known and categorized as traditional. Moreover, scholars propose that using expanded violin-playing techniques is more limited than other techniques are for various reasons. However, such techniques belong to the 20th century and are used in contemporary works. This contradicting notion led researchers to question the current level of education in institutions of professional music education and to determine the approaches used by violin educators regarding this matter.

The study focuses on the fundamental problem of determining the status of the use of expanded violin-playing techniques in violin education of the 20th century. The study employed the survey method to conduct a case study and aimed to reveal the status of use of expanded violin-playing techniques based on the views of faculty members in undergraduate institutions of music education that offer occupational education. The research targeted faculty members, 30 of whom were selected. The participants are assigned to violin education in higher education institutions in Turkey. The list of the institutions to which the participating faculty members belong is as follows: Anatolian University, Balıkesir University, Bolu Abant İzzet Baysal University, Hacettepe University, İnönü University, İstanbul University, Okan University, İstanbul Technical University, Kocaeli University, Maltepe University, Marmara University, Mersin University, Mimar Sinan Fine Arts University, Trakya University, Yıldız Technical University, and Zonguldak Bülent Ecevit University.

The study searched for data in available national and international resources on expanded playing techniques of the 20th century and identified 60 techniques. Afterward, the 30 
violin instructors completed a 10-question survey that included four open-ended questions. The survey questions were devised under the guidance of two experts in music. Responses were analyzed using two statistical techniques, namely, frequency and percentage distribution. Responses, which were coded and conceptualized, to openended questions were subject to content analysis. The frequency of use of concepts was calculated.

In line with the overall objective of the study, the following questions were presented:

1. Which of the expanded playing techniques of the 20th century are used and how frequently?

2. How many etudes/pieces and instructional books used by faculty members include these techniques?

3. What is your opinion regarding the necessity of teaching expanded playing techniques of the 20th century regarding instrument lessons in individual courses dedicated to the topic and the importance of including them in the curriculum?

4. What is your opinion on the methods used in teaching current violin-playing techniques?

5. What is your opinion regarding the sufficiency of student profiles for modern violinplaying techniques (in terms of readiness, sufficient performance in using traditional techniques and with regard to willingness and readiness to learn expanded playing techniques)?

6. What is your opinion regarding the involvement of modern expanded violin techniques in the instruction process?

7. What is your opinion on the level of knowledgeability and competency of violin instructors educated in Turkey in terms of teaching modern expanded playing techniques?

The study qualitatively determined the status and frequency of using modern techniques in line with the study results and with the views of the participants. The study found that a Bartok pizzicato and a right-hand touch pizzicato were the most frequently used techniques, whereas using a mallet and a glass stick to strike the strings were the least 
common. Moreover, the study found that the number of etudes/pieces used for teaching ranges between one and five. A majority of instructors do not use instructional books, considered necessary or useful in teaching the techniques in instrument lessons. Furthermore, the techniques should be taught in separate courses dedicated to the subject, whereas the most suitable method for teaching is demonstration. The student profile is insufficient in terms of readiness, which rendered students unable to become involved in the process of learning. The teaching of expanded techniques should be included in the curriculum. Last, the study suggests that violin instructors educated in Turkey lack sufficient knowledge about the subject and are less equipped to conduct instruction. 


\section{Giriş}

20. yüzyıl genişletilmiş keman çalma teknikleri, müzik tarihi içerisinde keman ve yayın gelişimini tamamlamasının ardından, çalgıcıların teknik ve müzikal gelişimlerinin yanı sıra bestecilerin müzik yazımlarında farklı ses, tını arayışlarına yönelmesinin doğal sonucu olarak ortaya çıkan, günümüzde 'geleneksel' olarak adlandırılabilecek çalma tekniklerini de kapsayan, bir ya da birkaçının birleşimi ve uzantısı olan ve bunlara eklenen yeni çalma şekilleri olarak karşımıza çıkmaktadır. Knox’un (2018, s. 8), “Konservatuvarlar genellikle 1650-1900 yılları arasında tanımlanmış, tonal sistemin oluşumu ve çözülmesi arasındaki dönemin teknik ve repertuvarlarına odaklanmıştır” tanımından yola çıkarak 'geleneksel' olarak adlandırabileceğimiz çalma teknikleri genel olarak tonal sistem ve bu dönem içinde kullanılan çalma teknikleri, genişletilmiş çalım teknikleri ise bu dönemden sonra gerçekleşen yeniliklere paralel olarak geleneksel çalma tekniklerinin gelişimi ve uzantısı şeklinde tanımlanabilir.

“Çalg1 tekniklerinde görülen gelişmelerle birlikte bazı besteciler, kemanı 'geleneksel' olarak kullanırken, diğerleri enstrümanın ses potansiyelini geleneksel çalma tekniklerinin modifikasyonları ve genişletmeleri, ayrıca yeni tekniklerin geliştirilmesi ve teknoloji kullanımı yoluyla genişletmeyi seçmişlerdir” (Ho, 2006, s. 1). Karşılaşılan çeşitli yaklaşım ve süreçlerle ilgili genel olarak "geleneksel neo-romantik yazı, minimalizm, modernizm, batı dışı müzik unsurlarının entegrasyonu, popüler müzik, belirsizlik ve modern teknolojisine sahip bir ara yüzün devam eden gelişimi” (Ho, 2006, s. 2), şeklinde sinıflandirarak bahsedilmektedir.

“20. yüzyıl boyunca birçok besteci, geleneksel çalgılar üzerinde yeni çalma teknikleri geliştirmiş, geleneksel çalgıları değiştirmiş, geleneksel olmayan çalgılar kullanmış veya yenilerini icat etmişlerdir. Geleneksel çalgılar üzerindeki bu 'yeni' performans teknikleri sadece 20. yüzyılın icatları değil, aynı zamanda 19. yüzyıldan itibaren müzikte kurulan armonikler, glissando ve vurmalı sesler gibi tekniklerin uzantısıdır” (Ishii, 2005, s. 8).

Eğitim açısından baktığımızda, Knox’un (2018, s. 8), “Konservatuvarlar genellikle 1650-1900 yılları arasında tanımlanmış, tonal sistemin oluşumu ve çözülmesi arasındaki dönemin teknik ve repertuvarlarına odaklanmıştır. Sonuç olarak genişletilmiş teknikleri içeren parçalarla karşılaşan çalgıcılar kendini yollarını bulmak zorunda kalır ve bu şekilde kazanılan bilgi her zaman başkalarına aktarılamaz" yaklaşımıyla bu tekniklerin öğretilmesine ilişkin pedagojik stratejiler üzerinde durduğu bir çalışması bulunmaktadır. $\mathrm{Bu}$ 
nedenler, Türkiye'deki durumun da incelenerek, gerektiği takdirde bu çalışmalara pedagojik yaklaşımlar geliştirilmesinin yararlı olabileceğini düşündürmektedir.

Türkiye'de yapılan çalışmaların içinde, genişletilmiş çalma tekniklerinin temelini oluşturan geleneksel teknikler üzerine yapılmış çalışmalara örnek olarak; Biricik'in (1998), keman sağ el tekniğinin Galamian ve Rus okullarından örneklerle incelenmesi, Merdinli'nin (1998), keman sol el tekniğinin Galamian ve Rus okullarından örneklerle incelenmesi, Ulucan'in (2005), kemanda yay tekniğinin temel bilgileri ve gelişimi, Kollo'nun (2016), 17. ve 18. yüzyılda keman çalma tekniklerinin gelişimi çalışmaları gösterilebilir.

20. yüzy1l genişletilmiş çalma tekniklerini içeren örnekler olarak; Stone'un (1980), Porta'nın (1985), Strange'in (2001), Tischhauser'un (2002), Vincent'in (2003), Ho'nun (2006), Danio'nun (2010), Karcilığlu'nun (2011 ve 2018), Arditti ve Platz'ın (2013), Sevsay'ın (2015) ve Knox'un (2018) çalışmaları gösterilebilir. Bu çalışmalar arasında genişletilmiş keman çalım teknikleri ve bu teknikleri içeren eserlerden alınmış örnekler de bulunmakta, aynı örneklerin farklı çalışmalarda kullanıldığı da görülebilmektedir.

Türkiye'de, klasik batı müziği alanında eğitim veren kurumlarda, temel olarak verilen çalg1 eğitiminin, repertuvar ve müfredat açısından geleneksel olarak adlandırabileceğimiz teknikleri içerdiği bilinmekle birlikte, 20. yüzyıl genişletilmiş çalma tekniklerinin eğitimde kullanım durumunu belirlemek için keman alanında eğitim veren eğitimcilerin konu ile ilgili görüşlerine başvurulması gerektiği düşünülmüştür.

\section{Problem}

Türkiye'de; klasik batı müziği alanında lisans düzeyinde verilen keman eğitimi, konservatuvarlar, güzel sanatlar fakülteleri, eğitim fakülteleri, müzik ve sahne sanatları fakülteleri ve sanat ve tasarım fakülteleri gibi mesleki müzik eğitimi veren kurumlarda yürütülmekte ve temel olarak verilen eğitiminin 'geleneksel' olarak adlandırabileceğimiz teknikleri içerdiği bilinmektedir. Genişletilmiş çalma tekniklerinin kullanımının ise çeşitli nedenlerden dolayı diğer tekniklere göre daha az düzeyde olduğu düşünülmektedir. 20. yüzyıl genişletilmiş çalma tekniklerinin günümüzde seslendirilen çağdaş eserlerde kullanıldığ1 görülmektedir. Bu durum araştırmacıları profesyonel müzik eğitimi verilen kurumların eğitim düzeylerinin güncelliği ve yeterliliği konusunda bir sorgulamaya ve keman eğitimcilerinin bu konuya yaklaşımını belirlemeye yöneltmiştir. Bu çalışmanın 
temel problemini, 20. yüzyıl genişletilmiş keman çalma tekniklerinin eğitimde kullanım durumunun ortaya konulması konusu oluşturmaktadır.

\section{Amaç}

$\mathrm{Bu}$ araştırma, öğretim elemanlarının görüşlerine göre lisans düzeyinde mesleki eğitim verilen müzik eğitimi kurumlarında genişletilmiş keman çalma tekniklerinin kullanım durumunun ortaya konulması amaçlanmıştır. Araştırmanın temel amacı doğrultusunda aşağıdaki sorulara cevap aranmıştır:

1. 20. yüzyıl genişletilmiş keman çalma tekniklerinden hangileri ne kadar sıklıkta kullanılmaktadır?

2. 20. yüzyıl genişletilmiş keman çalma tekniklerini içeren etütler/eserlerin ve öğretici kitapların sayıca kullanım durumu nasıldır?

3. 20. yüzyıl genişletilmiş keman çalma tekniklerinin çalgı derslerinde öğretilmesi, ayrı bir ders olarak öğretilmesi ve müfredatta bulunması gerekliliği konusundaki görüşleri nasıldır?

4. 20. yüzyıl genişletilmiş keman çalma tekniklerinin hangi yöntemlerle öğretilmesi gerektiği konusundaki görüşleri nasıldır?

5. 20. yüzyıl genişletilmiş keman çalma teknikleri konusunda öğrenci profillini yeterli bulma (hazır bulunuşluk; geleneksel çalma teknikleri konusunda yeterlik göstermiş ve genişletilmiş çalma tekniklerini öğrenmeye hazır bulunma) durumu nasıldır?

6. 20. yüzyıl genişletilmiş keman çalma tekniklerinin öğretim sürecine dahil olabilmesi konusundaki görüşleri nasıldır?

7. 20. yüzyıl genişletilmiş keman çalma tekniklerinin öğretimi konusunda Türkiye'de yetişen keman eğitmenlerinin bilgi ve donanımlarını yeterli bulma durumu nasıldır?

\section{Sinırlılıklar}

$\mathrm{Bu}$ çalışma lisans düzeyi daha üst yetkinlik sağladığından dolayı bu düzeyde eğitim veren konservatuvarlar, güzel sanatlar fakülteleri, eğitim fakülteleri, müzik ve sahne sanatları fakülteleri ve sanat ve tasarım fakülteleri, konu ile ilgili olarak, araştırmacının ulaşabildiği ulusal ve uluslararası kitap, hakemli dergi, lisansüstü tez çalışmaları gibi 
kaynaklar, çeşitliliği sağlamak amacıyla örnek olarak seçilen 60 farklı keman çalma tekniği, tekniklerin eğitimde kullanım durumuna yönelik anket ve anketin uygulandığı 30 keman eğitimcisi ile sınırlıdır.

\section{Yöntem}

Araştırma tarama modeli bir araştırma olup, 20. yüzyıl genişletilmiş keman çalma tekniklerinin eğitimde kullanım durumunun belirlenmesi amacını taşımaktadır. "Tarama modeli, geçmişte ya da halen var olan bir durumu var olduğu şekliyle betimlemeyi amaçlayan araştırma yaklaşımıdır” (Karasar, 2000, s. 77). Araştırmanın evrenini Türkiye'de mesleki müzik eğitimi verilen yüksek öğretim kurumlarında keman eğitimi veren öğretim elemanları oluşturmaktadır. Araştırma örneklemi ise Türkiye'deki mesleki müzik eğitimi verilen yüksek öğretim kurumlarında keman eğitimi veren 30 öğretim elemanından oluşmaktadır.

Tablo 1. Örneklem grubunda yer alan eğitimcilerin eğitim aldıkları lisans programlarına göre yüzde ve frekans dağılımı

\begin{tabular}{|l|c|c|}
\hline Eğitim Alınan Lisans Programları & n & \% \\
\hline Eğitim Fakültesi & 7 & 23.3 \\
\hline Güzel Sanatlar Fakültesi & 1 & 3.3 \\
\hline İstanbul Üniversitesi İletişim Fakültesi & 1 & 3.3 \\
\hline Konservatuvar & 19 & 63.3 \\
\hline Sahne Sanatları Fakültesi & 1 & 3.3 \\
\hline Viyana Müzik Üniversitesi & 1 & 3.3 \\
\hline Toplam & 30 & 100.0 \\
\hline
\end{tabular}

Tablo 1 incelendiğinde, örneklem grubunda yer alan eğitimcilerin eğitim aldıkları lisans programlarında; en fazla sayıyı (\%63.3) konservatuvar eğitimi alanlar oluşturmakta, İstanbul Üniversitesi İletişim Fakültesi’nde eğitim almış 1 (\%3.3) eğitimci olduğu göze çarpmaktadır.

Tablo 2. Örneklem grubunda yer alan eğitimcilerin eğitim aldıkları yüksek lisans programlarına göre yüzde ve frekans dağ 11 lımı

\begin{tabular}{|l|c|c|}
\hline Yüksek lisans programları & f & $\mathbf{\%}$ \\
\hline Eğitim Fakültesi & 8 & 26.7 \\
\hline Güzel Sanatlar Fakültesi & 3 & 5.3 \\
\hline Konservatuvar & 16 & 10.0 \\
\hline Sahne Sanatları Fakültesi & 1 & 3.3 \\
\hline Viyana Müzik Üniversitesi & 1 & 3.3 \\
\hline Yurtdış1 & 1 & 3.3 \\
\hline Toplam & 30 & 100.0 \\
\hline
\end{tabular}


Tablo 2 incelendiğinde, örneklem grubunda yer alan eğitimcilerin eğitim aldıkları yüksek lisans programlarında; en fazla sayıyı konservatuvar (\%10), en az sayıyı Sahne Sanatları Fakültesi, Viyana Müzik Üniversitesi ve yurtdışı yüksek lisans (\%3.3) eğitimi alanların oluşturduğu görülmektedir.

Tablo 3. Örneklem grubunda yer alan eğitimcilerin eğitim aldıkları doktora/ sanatta yeterlik programlarına göre yüzde ve frekans dağılımı

\begin{tabular}{|l|c|c|}
\hline Doktora/sanatta yeterlik & f & $\mathbf{\%}$ \\
\hline Eğitim Bilimleri Enstitüsü & 6 & 20.0 \\
\hline Güzel Sanatlar Enstitüsü & 2 & 6.7 \\
\hline Sosyal Bilimler Enstitüsü & 13 & 43.3 \\
\hline Yok & 8 & 26.7 \\
\hline Yurtdış1 & 1 & 3.3 \\
\hline Toplam & 30 & 100.0 \\
\hline
\end{tabular}

Tablo 3 incelendiğinde, örneklem grubunda yer alan eğitimcilerin eğitim aldıkları doktora/ sanatta yeterlik programlarında; en fazla sayının (\%43.3) Sosyal Bilimler Enstitüsü, en az sayının (\%3.3) yurtdışında eğitim olduğu, (\%26.7) doktora/sanatta yeterlik eğitimi almamış oldukları görülmektedir.

Tablo 4. Örneklem grubunda yer alan eğitimcilerin görev yerlerine göre yüzde ve frekans dağ 1 lımı

\begin{tabular}{|l|c|c|}
\hline Görev yerleri & f & \% \\
\hline Anadolu Üniversitesi & 1 & 3.3 \\
\hline Balıkesir Üniversitesi & 1 & 3.3 \\
\hline Bolu Abant İzzet Baysal Üniversitesi & 2 & 6.7 \\
\hline Eğitim Fakültesi & 1 & 3.3 \\
\hline Hacettepe Üniversitesi & 1 & 3.3 \\
\hline İnönü Üniversitesi & 3 & 10.0 \\
\hline İstanbul Üniversitesi & 6 & 20.0 \\
\hline İstanbul Üniversitesi / Okan Üniversitesi & 1 & 3.3 \\
\hline İstanbul Teknik Üniversitesi & 1 & 3.3 \\
\hline Kocaeli Üniversitesi & 3 & 10.0 \\
\hline Maltepe Üniversitesi & 1 & 3.3 \\
\hline Marmara Üniversitesi & 1 & 3.3 \\
\hline Mersin Üniversitesi & 3 & 10.0 \\
\hline Mimar Sinan Güzel Sanatlar Üniversitesi & 1 & 3.3 \\
\hline Okan Üniversitesi & 1 & 3.3 \\
\hline Trakya Üniversitesi & 1 & 3.3 \\
\hline Yıldı Teknik Üniversitesi & 1 & 3.3 \\
\hline Zonguldak Bülent Ecevit Üniversitesi & 1 & 3.3 \\
\hline Toplam & 30 & 100.0 \\
\hline
\end{tabular}


Tablo 4 incelendiğinde, örneklem grubunda yer alan eğitimcilerin görev yerlerinin; (\%20 .0) İstanbul Üniversitesi, (\%10.0) İnönü Üniversitesi, (\%10.0) Kocaeli Üniversitesi, (\%10.0) Mersin Üniversitesi, (\%6.7) Bolu İzzet Baysal Üniversitesi olduğu, diğer üniversitelerde görev yapanların (\%3.3) olduğu görülmektedir.

\begin{tabular}{|l|c|c|}
\hline \multicolumn{3}{|c|}{ Tablo 5. Örneklem grubunda yer alan eğitimcilerin akademik unvanlarına göre } \\
yüzde ve frekans dağılımı
\end{tabular}

Tablo 5 incelendiğinde, örneklem grubunda yer alan eğitimcilerin akademik unvanlarının büyük çoğunluğun öğretim görevlisi, en az yoğunluğun araştırma görevlisi şeklinde olduğu görülmektedir.

\section{Veri Toplama Araçları ve Analizi}

Araştırmada 20. yüzyıl genişletilmiş çalma teknikleri ile ilgili ulaşılabilen ulusal ve uluslararası kitap, hakemli dergi, lisansüstü tez çalışmaları gibi kaynaklar incelenerek literatürde yer alan genişletilmiş keman çalma teknikleri üzerine çalışmalar tespit edilmiştir. Bu çalışmalarda genişletilmiş keman çalım teknikleri ve bu teknikleri içeren eserlerden alınmış örnekler bulunmakta, aynı örneklerin farklı çalışmalarda kullanıldığı görülebilmektedir. Farklı tekniklerin birlikte kullanımı ise birbirine benzer örnekler ortaya çıkarmaktadır. $\mathrm{Bu}$ kaynaklarda yer alan teknikler incelendiğinde yaklaşık olarak, Strange (2001) 187 adet, Sevsay (2015) 80 adet, Arditti ve Platz (2013) 70 adet, Karcılığlu (2018) 39 adet, Stone (1980) 30 adet, Vincent (2003) 18 adet tekniğe yer vermiştir. Bu tekniklerden eserlerde sıklıkla kullanılan ve farklı olarak nitelendirilebilecek teknikler incelenerek, birbirine benzer tekniklerden sadeleştirilerek örnek olarak seçilen 60 farklı genişletilmiş çalım tekniği tarama yöntemiyle derlenerek, 20. yüzyıl genişletilmiş keman çalma tekniklerinin eğitimde kullanım durumunu belirlemeye yönelik 4'ü açık uçlu olmak üzere 10 sorudan oluşan bir anket 30 keman eğitimcisine uygulanmıştır. Anket soruları müzik alanında iki uzmandan görüş alınarak hazırlanmıştır. Verilerin analizi için katılımcıların verdikleri cevaplar incelenerek, istatistiksel tekniklerden frekans ve yüzde dağılımlarından faydalanılmıştır. Açık uçlu sorularda eğitimci görüşlerini içeren cevapların içerik analizi yapılarak içerikler kodlanmış ve kavramsallaştırılmıştır. Kavramların kullanılma sıklıkları hesaplanmıştır. 


\section{Bulgular}

Tablo 6. 20. yüzyıl genişletilmiş keman çalma tekniklerinin eğitimde kullanım durumuna göre yüzde ve frekans değerleri

\begin{tabular}{|c|c|c|c|}
\hline Teknikler & f & $\begin{array}{c}\text { Kişi } \\
\text { sayısına göre\% }\end{array}$ & $\begin{array}{l}\text { Toplam teknik } \\
\text { sayısına } \\
\text { göre } \%\end{array}$ \\
\hline Bartok pizzicato & 19 & 63.3 & 6.0 \\
\hline Sağ elle çekerek pizzicato & 19 & 63.3 & 6.0 \\
\hline Yayın köprü ve kuyruk arası çalma & 17 & 56.7 & 5.3 \\
\hline Fazla basınçlı yay kullanımı & 14 & 46.6 & 4.4 \\
\hline Değişken vibrato & 13 & 43.3 & 4.1 \\
\hline Birden çok sesin aynı anda pizzicato çalma & 12 & 40.0 & 3.8 \\
\hline Yay kökünde kılları tellere vurarak (doğrar gibi) çalma & 12 & 40.0 & 3.8 \\
\hline Ölçüsüz ve ritmsiz tremolo & 10 & 33.3 & 3.1 \\
\hline Glissando triller & 10 & 33.3 & 3.1 \\
\hline Fırlatılmış yay (col legno batuto) kullanımı & 10 & 33.3 & 3.1 \\
\hline Uzun süreli (sürdürülebilir) yay kullanımı & 9 & 30.0 & 2.8 \\
\hline Alt armonikler & 8 & 26.7 & 2.5 \\
\hline Mikro tonlar & 8 & 26.7 & 2.5 \\
\hline Yay tahtası ile glissando & 8 & 26.7 & 2.5 \\
\hline Sol el glissando ve col legno battuto & 7 & 23.3 & 2.2 \\
\hline Yayın köprüdeki ahşap surdin üzerinde çalması & 7 & 23.3 & 2.2 \\
\hline Yayın yanal kullanımı & 7 & 23.3 & 2.2 \\
\hline Çift ses zit yönlü glissando & 6 & 20.0 & 1.9 \\
\hline Farklı hizlarda glissando & 6 & 20.0 & 1.9 \\
\hline Fırçalama & 6 & 20.0 & 1.9 \\
\hline Sağ el ile keman gövdesine kap1 vurur gibi çalma & 6 & 20.0 & 1.9 \\
\hline Sağ el parmaklarla tremolo & 6 & 20.0 & 1.9 \\
\hline Sol el çekiçleme & 6 & 20.0 & 1.9 \\
\hline Sol el çıkıc1/ inici seslerle pizzicato & 6 & 20.0 & 1.9 \\
\hline Armonik (flajöle) pizzicato & 5 & 16.7 & 1.6 \\
\hline Sağ el parmakla vurarak çalma & 5 & 16.7 & 1.6 \\
\hline Ses perdeleri belirsiz arpej & 5 & 16.7 & 1.6 \\
\hline Sol el yaysız trill çalma & 5 & 16.7 & 1.6 \\
\hline Yay baskısıyla ses perdesini kaydırma & 5 & 16.7 & 1.6 \\
\hline Yayın dairesel kullanımı & 5 & 16.7 & 1.6 \\
\hline Armonik trill & 4 & 13.3 & 1.3 \\
\hline Köprü arkası col legno battuto çalma & 4 & 13.3 & 1.3 \\
\hline Köprü üzerinde pizzicato çalma & 4 & 13.3 & 1.3 \\
\hline Sağ el tırnak pizzicato & 4 & 13.3 & 1.3 \\
\hline Sağ el yüksük tremolo & 4 & 13.3 & 1.3 \\
\hline Sallanan (dalgalı) glissando & 4 & 13.3 & 1.3 \\
\hline Çift yönlü pizzicato tremolo glissando & 3 & 10.0 & 0.9 \\
\hline Mikro ton armonikler & 3 & 10.0 & 0.9 \\
\hline
\end{tabular}




\begin{tabular}{|l|c|c|c|}
\hline Ölçüsüz ve ritimsiz tremolo & 3 & 10.0 & 0.9 \\
\hline Telin haricinde yay ile çalma & 3 & 10.0 & 0.9 \\
\hline Yayın tellerin altından çalma & 3 & 10.0 & 0.9 \\
\hline Kuyrukta yay ile çalma & 2 & 6.7 & 0.6 \\
\hline Martı glissando & 2 & 6.7 & 0.6 \\
\hline Sağ el avuç içiyle çalma & 2 & 6.7 & 0.6 \\
\hline Le pizzicato effleuré & 2 & 6.7 & 0.6 \\
\hline Sağ el avuçiçiyle vurarak çalma & 2 & 6.7 & 0.6 \\
\hline Sağ el parmak ucuyla vurarak çalma & 2 & 6.7 & 0.6 \\
\hline Yapay armonik glissando & 2 & 6.7 & 0.6 \\
\hline Yayın salyangozda çalma & 2 & 6.7 & 0.6 \\
\hline Yayın sol el arkasında (mandallar yakınında) çalma & 2 & 6.7 & 0.6 \\
\hline Malet kullanımı & 1 & 3.3 & 0.3 \\
\hline Cam çubukla tellere vurarak çalma & 1 & 3.3 & 0.3 \\
\hline Flautando & 1 & 3.3 & 0.3 \\
\hline Ahşap dübel ile vurarak teller arasında çalma & 1 & 3.3 & 0.3 \\
\hline Çift ses armonik (flajöle) & 1 & 3.3 & 0.3 \\
\hline Çift ses armonik glissando & 1 & 3.3 & 0.3 \\
\hline Köprü arkası pizzicato çalma & 1 & 3.3 & 0.3 \\
\hline Sol el ile gövdede tremolo çalma & 1 & 3.3 & 0.3 \\
\hline Yay vidası ile tellere dokunarak çalma & 1 & 3.3 & 0.3 \\
\hline Toplam seçim sayısı & 318 & & 100 \\
\hline
\end{tabular}

Tablo 6 incelendiğinde, 20. yüzyıl genişletilmiş çalma tekniklerinin eğitimde kullanım durumuna göre; en çok kullanılan tekniklerin Bartok pizzicato ve sağ elle çekerek pizzicato (\%63.3), en az kullanılanların malet kullanımı, cam çubukla tellere vurma, flautando, ahşap dübel ile vurarak çalma, çift ses armonik flajöle, çift ses armonik glissando, köprü arkası pizzicato çalma, sol el ile gövdede tremolo çalma, yay vidası ile tellere dokunarak çalma (\%3.3) gibi teknikler olduğu görülmektedir.

Tablo 7. 20. yüzyıl genişletilmiş keman çalma tekniklerini içeren eser/etüt kullanım sayısına göre yüzde ve frekans değerleri

\begin{tabular}{|l|c|c|}
\hline Kaç etüt/eser kullanıldı̆̆ı & f & \% \\
\hline 0 (Kullanmıyorum) & 8 & 26.6 \\
\hline $1-5$ & 13 & 43.3 \\
\hline 10 ve üstü & 5 & 16.7 \\
\hline $5-10$ & 1 & 3.3 \\
\hline Özel bir etüt yok çalınan eserin içinde geçerse kullanıyoruz. & 3 & 9.9 \\
\hline
\end{tabular}

Tablo 7 incelendiğinde, 20. yüzyıl genişletilmiş çalma tekniklerini içeren; en çok 1-5 arası sayıda eser/etüt, en az 5-10 arası sayıda eser/etüt kullanıldığı göze çarpmaktadır. 
Tablo 8. 20. yüzyıl genişletilmiş keman çalma teknikleri ve bunların öğretimi ile ilgili kullanılan öğretici kitaplara (metot/repertuvar/teknik içerikli) göre yüzde ve frekans değerleri

\begin{tabular}{|c|c|c|c|}
\hline Öğretici kitaplar & f & $\begin{array}{c}\text { Cevap sayısına } \\
\text { göre\% }\end{array}$ & $\begin{array}{c}\text { Kişi } \\
\text { sayısına göre\% } \\
\end{array}$ \\
\hline Kitap Kullanmayanlar & 16 & 24.2 & 53.3 \\
\hline Mevcut Olan Metot ve Eserler & 2 & 3.0 & 6.7 \\
\hline Çalımı Kolay Küçük Eserler & 1 & 1.5 & 3.3 \\
\hline C. Flesh- scales & 4 & 6.1 & 13.3 \\
\hline R.Kreutzer -Etütler & 2 & 3.0 & 6.7 \\
\hline J.F.Mazas- Etüt & 2 & 3.0 & 6.7 \\
\hline P. Rode- Caprices & 2 & 3.0 & 6.7 \\
\hline J. Dont- Etüt & 2 & 3.0 & 6.7 \\
\hline H. Schradieck- technics & 3 & 4.5 & 10.0 \\
\hline N. Paganini Caprices & 2 & 3.0 & 6.7 \\
\hline O.Sevcik -technics & 1 & 1.5 & 3.3 \\
\hline P. Gavinies- etütler & 1 & 1.5 & 3.3 \\
\hline I. Galamian- technics & 2 & 3.0 & 6.7 \\
\hline F.David -etütler & 1 & 1.5 & 3.3 \\
\hline C.A.Beriot & 1 & 1.5 & 3.3 \\
\hline L. Auer & 2 & 3.0 & 6.7 \\
\hline E. Ysaye & 1 & 1.5 & 3.3 \\
\hline E. Mahler Rapsodia & 1 & 1.5 & 3.3 \\
\hline C. Dancla- Air Variations & 2 & 3.0 & 6.7 \\
\hline C. Dancla- Etütler & 2 & 3.0 & 6.7 \\
\hline İlhan Usmanbaş- Keman Konçertosu & 1 & 1.5 & 3.3 \\
\hline Çeşitli orkestra eserlerinin keman partileri & 1 & 1.5 & 3.3 \\
\hline Joachim-Moser Violin School & 1 & 1.5 & 3.3 \\
\hline Elizabeth Gilels -Scales \& Arpeggios & 2 & 3.0 & 6.7 \\
\hline E. Polo- 30 Estudios en Cuerdas Dobles & 1 & 1.5 & 3.3 \\
\hline B. Bartok- 6 Romanian Dances for Violin & 1 & 1.5 & 3.3 \\
\hline E. Grieg- Violin Sonatas & 1 & 1.5 & 3.3 \\
\hline P. Sarasate -Violin Pieces & 1 & 1.5 & 3.3 \\
\hline G. Faure-Violin Sonatas, Sicilienne for Violin, Andante & 1 & 1.5 & 3.3 \\
\hline E. Elgar-Violin Concerto, Violin Sonata & 1 & 1.5 & 3.3 \\
\hline C. Debussy- Clair de Lune, Violin Sonata & 1 & 1.5 & 3.3 \\
\hline A. Glazunov- Violin Concerto & 1 & 1.5 & 3.3 \\
\hline J. Sibelius-Violin Concerto & 1 & 1.5 & 3.3 \\
\hline S.Rachmaninov -Vocalise & 1 & 1.5 & 3.3 \\
\hline M.de Falla- Spanish Dance & 1 & 1.5 & 3.3 \\
\hline B. Akdeniz- Keman Eğitimine Yeni Bir Yaklaşım & 1 & 1.5 & 3.3 \\
\hline
\end{tabular}

Tablo 8 incelendiğinde, alan uzmanlarının 20. yüzyıl genişletilmiş keman çalma teknikleri ve bunların öğretimi ile ilgili olarak; çoğunluğun öğretici bir kitap kullanmadığ1 göze çarpmaktadır. 
Tablo 9. 20. yüzyıl genişletilmiş keman çalma tekniklerinin çalgı derslerinde öğretilmesi ile ilgili eğitimci görüşlerine göre yüzde ve frekans değerleri

\begin{tabular}{|l|c|c|c|}
\hline Çalgı dersinde öğretimi & f & $\begin{array}{c}\text { Cevap } \\
\text { sayısına } \\
\text { göre \% }\end{array}$ & $\begin{array}{c}\text { Kişi } \\
\text { sayısına } \\
\text { göre \% }\end{array}$ \\
\hline Yetersiz & 2 & 5.9 & 6.7 \\
\hline Zorunlu ya da seçmeli ders olmalı & 2 & 5.9 & 6.7 \\
\hline Metot ve eserle destekleyerek & 5 & 14.7 & 16.7 \\
\hline Gerekli/ Faydalı olur & 12 & 35.3 & 40.0 \\
\hline Eser içinde gerekliyse uygulanmalı & 4 & 11.8 & 13.3 \\
\hline Diğer tekniklerle bütün olarak & 1 & 2.9 & 3.3 \\
\hline Öğrencinin tercihine göre & 1 & 2.9 & 3.3 \\
\hline Bu alanda özelleşmiş eğitmenler tarafından öğretilmeli & 3 & 8.8 & 10.0 \\
\hline Lisans / doktora düzeyinde öğretilmeli & 4 & 11.8 & 13.3 \\
\hline
\end{tabular}

Tablo 9 incelendiğinde, örneklem grubunda yer alan eğitimcilerin 20. yüzyıl genişletilmiş çalma tekniklerinin çalgı derslerinde öğretilmesi ile ilgili görüşlerinde; en yüksek oran (\%35.3), faydalı ve gerekli olduğu, en düşük oranlar öğrencinin tercihine göre ve diğer tekniklerle bütün olarak (\%2.9) şeklindedir.

Tablo 10. Eğitimcilerin 20. yüzyıl genişletilmiş keman çalma tekniklerinin ayrı bir ders olarak ögretilmesi konusundaki görüşlerine göre yüzde ve frekans değerleri

\begin{tabular}{|l|c|c|}
\hline Ayrı bir derste öğretimi & f & \% \\
\hline Evet, ayrı bir ders olarak bölüm programlarında yer alması uygun olur. & 16 & 53.3 \\
\hline Hayır, çalgı eğitimi derslerinde verilmesi yeterli olabilir. & 9 & 30.0 \\
\hline Kararsız & 2 & 6.7 \\
\hline $\begin{array}{l}\text { Yüksek Lisans veya Doktora düzeyinde ayrı bir ders olarak yer verilmesi } \\
\text { yararlı olur }\end{array}$ & 3 & 10.0 \\
\hline
\end{tabular}

Tablo 10 incelendiğinde, örneklem grubunda yer alan eğitimcilerin 20. yüzyıl genişletilmiş çalma tekniklerinin ayrı bir ders olarak öğretilmesi ile ilgili görüşlerinde; en yüksek oran $(\% 53.3)$ bu tekniklerin ayrı bir ders olarak bölüm programlarında yer alması, en düşük oran (\%6.7) kararsız olduğu şeklindedir.

Tablo 11. Eğitimcilerin 20. yüzyıl genişletilmiş keman çalma tekniklerinin öğretimi konusunda müfredatta bulunması gerekliliği durumuna göre yüzde ve frekans değerleri

\begin{tabular}{|l|c|c|}
\hline Müfredatta bulunması & f & \% \\
\hline Gerekli & 26 & 86.7 \\
\hline Gereksiz & 4 & 13.3 \\
\hline Toplam & 30 & 100.0 \\
\hline
\end{tabular}

Tablo 11 incelendiğinde, örneklem grubunda yer alan eğitimcilerin 20. yüzyıl genişletilmiş çalma tekniklerinin öğretimi konusunda müfredatta bulunmasını; 26 kişinin (\%86.7) gerekli bulduğu, 4 kişinin (\%13.3) gerekli bulmadığı görülmektedir. 
Tablo 12. Eğitimcilerin 20. yüzyıl genişletilmiş keman çalma tekniklerinin hangi yöntemlerle öğretilmesi gerektiğgi ile ilgili eğitimci görüşlerine ilişkin frekans ve yüzde değerleri

\begin{tabular}{|l|c|c|c|}
\hline Öğretim yöntemi & f & $\begin{array}{c}\text { Cevap } \\
\text { sayısına } \\
\text { göre\% }\end{array}$ & $\begin{array}{c}\text { Kişi } \\
\text { sayısına } \\
\text { göre\% }\end{array}$ \\
\hline Eser İnceleme & 2 & 4.3 & 6.7 \\
\hline $\begin{array}{l}\text { Çağdaş Müziği Kuramsal Olarak İyi Öğretme (kompozisyon dersini } \\
\text { vermekte olan öğretim elemanı ile birlikte) }\end{array}$ & 5 & 10.6 & 16.7 \\
\hline Besteci ile Eser Provası & 3 & 6.4 & 10.0 \\
\hline Dinleme & 1 & 2.1 & 3.3 \\
\hline Farklı Materyal Geliştirme & 3 & 6.4 & 10.0 \\
\hline Uygulayarak Gösterme / Örneklendirme & 15 & 31.9 & 50.0 \\
\hline Bu Ĕgitimi Alan (alanda uzman) Eğitimciden & 5 & 10.6 & 16.7 \\
\hline Farklı Eserler Üzerinde Çalışarak & 8 & 17.0 & 26.7 \\
\hline Disiplinli Çalışma & 2 & 4.3 & 6.7 \\
\hline Temel Teknikler Oturduktan Sonra & 3 & 6.4 & 10.0 \\
\hline
\end{tabular}

Tablo 12 incelendiğinde, örneklem grubunda yer alan eğitimcilerin 20. yüzyıl genişletilmiş çalma tekniklerinin hangi yöntemlerle öğretilmesi ile ilgili görüşlerinde; eğitimcilerin yarısının en yüksek oran (\%50.0) ile uygulayarak gösterme/ örneklendirme yöntemini belirttikleri görülmektedir.

Tablo 13. Eğitimcilerin 20. yüzy1l genişletilmiş keman çalma tekniklerinin öğretimi konusunda öğrenci profilini yeterli bulma durumuna göre yüzde ve frekans değerleri

\begin{tabular}{|l|c|c|}
\hline Öğrenci profili & f & $\mathbf{\%}$ \\
\hline Yeterli & 12 & 40.0 \\
\hline Yetersiz & 18 & 60.0 \\
\hline Toplam & 30 & 100.0 \\
\hline
\end{tabular}

Tablo 13 incelendiğinde, örneklem grubunda yer alan eğitimcilerin 20. yüzyıl genişletilmiş çalma tekniklerinin öğretimi konusunda öğrenci profilini; 18 kişinin (\%60.0) yeterli bulmadığ 1,12 kişinin (\%40.0) yeterli bulduğu görülmektedir.

Tablo 14. Eğitimcilerin 20. yüzyıl genişletilmiş keman çalma tekniklerinin öğretim sürecine dahil olabilmesi durumuna göre yüzde ve frekans değerleri

\begin{tabular}{|l|c|c|}
\hline Öğrenme sürecine dahil olabilme & f & $\mathbf{\%}$ \\
\hline Yeterli & 10 & 33.3 \\
\hline Yetersiz & 20 & 66.7 \\
\hline Toplam & 30 & 100.0 \\
\hline
\end{tabular}

Tablo 14 incelendiğinde, örneklem grubunda yer alan eğitimcilerin 20. yüzyıl genişletilmiş çalma tekniklerinin öğretim sürecine dahil olabilmesi durumunu; 20 kişinin (\%66.7) yeterli bulmadığg1, 10 kişinin (\%33.3) yeterli bulduğu görülmektedir. 
Tablo 15. Eğitimcilerin 20. yüzyıl genişletilmiş keman çalma tekniklerinin öğretimi konusunda Türkiye'de yetişen keman eğitmenlerinin bilgi ve donanım yeterliliği durumuna göre yüzde ve frekans değerleri

\begin{tabular}{|l|c|c|}
\hline Uzmanların bilgi ve donanımı & f & $\mathbf{\%}$ \\
\hline Yeterli & 12 & 40.0 \\
\hline Yetersiz & 18 & 60.0 \\
\hline Toplam & 30 & 100.0 \\
\hline
\end{tabular}

Tablo 15 incelendiğinde, örneklem grubunda yer alan eğitimcilerin 20. yüzyıl genişletilmiş çalma tekniklerinin öğretimi konusunda Türkiye'de yetişen keman eğitimcilerinin bilgi ve donanım yeterliliğini; 18 kişinin (\%60.0) yeterli bulmadığı, 12 kişinin (\%40.0) yeterli bulduğu görülmektedir.

\section{Sonuç ve Tartışma}

Araştırmanın lisans eğitimi süresince 20. yüzyıl genişletilmiş keman çalım tekniklerinden hangileri ne kadar sıklıkta kullanılmaktadır sorusuna yönelik olarak; Tablo 6'da verildiği üzere elde edilen sonuçlara bakıldığında; elde edilen sonuçlara bakıldığında; en çok kullanılan tekniklerin her ikisinin de pizzicato olduğu en az kullanılan 'malet kullanımı', 'cam çubukla tellere vurma', 'flautando', 'ahşap dübel ile vurarak çalma', 'çift ses armonik flajöle', 'çift ses armonik glissando', 'köprü arkası pizzicato çalma', 'sol el ile gövdede tremolo çalma', 'yay vidası ile tellere dokunarak çalma' gibi tekniklerin ise çoğunlukla kemanın geleneksel çalınışı ve alışılmışın dışında olan yayın vidası, ahşap dübel, malet gibi farklı materyallerin kullanımını içeren teknikler olduğu göze çarpmaktadır. Bu tarz materyallerin kullanımının çalgıya zarar verebilme ihtimalinin de daha az tercih edilmesine neden olduğunu düşündürmektedir.

Araştırmanın öğretim elemanlarının genel olarak kullandığg 20 . yüzyıl genişletilmiş keman çalma tekniklerini içeren etüt/eserlerin sayıca durumu nasıldır sorusuna yönelik olarak, eğitimcilerin yaklaşık yarısının 1-5 arası eser/etüt kullandığı, yaklaşık dörtte birinin genişletilmiş çalma tekniklerine yönelik hiç eser kullanmadığg ve yine yaklaşık dörtte birinin 5-10 arası etüt/eser kullandığı anlaşılmıştır. Bu soruya yönelik olarak, elde edilen sonuçlara bakıldığında; araştırmanın diğer sorularında verilen cevaplara dayanarak, bu teknikleri içeren eser/etüt kullanmadığını belirten eğitimcilerin bu tekniklere yönelik eser/etüt kullanımına yer vermemesinin olası nedenleri, öğrenci profilinin yetersiz bulunması, lisans düzeyinde öğrencinin bulunmaması, yüksek lisans ve doktora düzeyinde ya da konservatuvarlarda öğretilmesi, program içeriklerinin yoğunluğu ve zaman 
yetersizliği gibi nedenlerdir. Öğrenci profilinin yetersiz bulunmasının başlıca nedenlerinden birinin de kurumların eğitim programlarının farklı amaçlara yönelik olması, bu sebeple eğitim fakültesi öğrencisi ile konservatuvar öğrencisi arasında düzey farklılıklar1 olduğu söylenebilir.

Araştırmanın öğretim elemanlarının 20. yüzyıl genişletilmiş keman çalma teknikleri ve bunların öğretimi ile ilgili kullandığı öğretici kitaplar hangileridir sorusuna yönelik olarak, Tablo 8'de verildiği üzere, eğitimcilerin yarısından fazlasının bu tekniklerin öğretimi ile ilgili bir kitap kullanmadığı göze çarpmaktadır. Bu soruya yönelik olarak, elde edilen sonuçlara bakıldığında; geleneksel yöntemlerle, gerekli ve mevcut olan metot ve eserlerin tercih edildiği görülmekle birlikte, kendi sağ ve sol el egzersizlerini geliştirip uygulatan eğitimciler olduğu görülmektedir. Bu durum hem farklı tekniklerin uygulanabilmesi için öncelikle geleneksel teknikler açısından zemin oluşturulması, hem de genişletilmiş çalma tekniklerinin öğretimi için farklı yöntemlere de ihtiyaç duyulabildiği şeklinde yorumlanabilir.

Araştırmanın öğretim elemanlarının 20. yüzyıl genişletilmiş keman çalma tekniklerinin çalgı derslerinde öğretilmesi konusundaki görüşleri nasıldır sorusuna yönelik olarak, Tablo 9'da verildiği üzere; en yüksek oran, bu tekniklerin çalgı dersinde öğretilmesinin faydalı ve gerekli olduğu görüşü yönündedir. Bu soruya yönelik olarak, elde edilen sonuçlara bakıldığında; eğitimcilerin bu tekniklerin çalgı derslerinde öğretimi ile ilgili gerekli/faydalı olduğunu belirtenlerin yanında metot ve eserle destekleyerek öğretilmesi gerektiği şeklinde görüşler olduğu görülmektedir. Metot ve eserle destekleme görüşünün diğer sorularda verilen müfredatta bulunması gerekliliğine ilişkin görüşlerle de örtüştügü ve buna yönelik ihtiyacın karşılanması adına bir önerme olduğu düşünülmektedir. Bunun yanında çalışılan kuruma göre öğrenci profilinin seviye ve ihtiyaçlarını gözeterek, müzisyen yetiştirilmesinde gerekli olduğunu belirten eğitimci görüşlerinin bulunduğu görülmektedir.

Araştırmanın öğretim elemanlarının 20. yüzyıl genişletilmiş keman çalma tekniklerinin bu konu ile ilgili ayrı bir ders olarak öğretilmesi konusundaki görüşleri nasıldır sorusuna yönelik olarak, Tablo 10'da verildiği üzere bu soruya yönelik olarak elde edilen sonuçlara bakıldığında; eğitimcilerin yaklaşık yarısı bu tekniklerin ayrı bir ders olarak yer almasını uygun bulurken, lisansüstü seviyede ayrı bir ders olarak verilmesi görüşünün \%10 oranında oluşu, diğer sorularda karşılaşılan ders programlarının yoğun oluşu, za- 
manın kısıtlılığ1, teorik olarak desteklenme ve öğrenci profilinin yeterli bulunmaması gibi görüşlerle örtüştügünü düşündürmektedir.

Araştırmanın öğretim elemanlarının mesleki eğitim verilen müzik eğitimi kurumlarında 20. yüzyıl genişletilmiş keman çalma tekniklerinin öğretimi konusunda müfredatta bulunması gerekliliği konusundaki görüşleri nasıldır sorusuna yönelik olarak, Tablo 11'de verildiği üzere elde edilen sonuçlara bakıldığında; müfredatta bulunması gerektiğini belirten eğitimcilerin sayıca çokluğu, bu alanda bilgi ve donanım düzeyinin yükseltilmesi istendiği ve bu tekniklerin öğretimine yönelik bir ihtiyaç bulunduğunu düşündürmektedir.

Araştırmanın öğretim elemanlarının 20. yüzyıl genişletilmiş keman çalma tekniklerinin hangi yöntemlerle öğretilmesi gerektiği konusundaki görüşleri nasıldır sorusuna yönelik olarak, Tablo 12'de verildiği üzere, eğitimcilerin yarısının en yüksek oranla (\%50.0) uygulayarak gösterme/ örneklendirme yöntemini belirttikleri görülmektedir. Bu tekniklerin öğretilme yöntemleri ile ilgili çoğunluğun, uygulayarak gösterme/örnekleme, fark11 eserler üzerinde çalışma, disiplinli çalışma gibi geleneksel tekniklerin öğretiminde de kullanılan yöntemler olduğu görülmektedir. Bu konu ile ilgili olarak; eserlerin incelenmesi, kompozisyon dersini vermekte olan öğretim elemanı ve eserlerin yaşıyorsa bestecileriyle prova yapılması şeklinde eğitimci görüşleri bulunduğu görülmektedir.

Araştırmanın öğretim elemanlarının mesleki eğitim verilen müzik eğitimi kurumlarında 20. yüzyıl genişletilmiş keman çalma tekniklerinin öğretimi konusunda öğrenci profilini yeterli bulma durumu nasıldır sorusuna yönelik olarak, Tablo 13'te gösterildiği üzere elde edilen bilgilere bakıldığında; öğrenci profilinin yetersiz bulunmasının önceki cevaplarda da belirtildiği üzere, bu tekniklerin lisansüstü seviyelerde veya konservatuvarlarda öğretilmesine ve geleneksel çalma tekniklerine hakimiyet gerektirdiği yönündeki cevaplarla desteklendiği, bunun yanında daha önce belirtildiği gibi eğitim kurumlarının amaçlarına yönelik olarak öğrenci düzeylerindeki farklılıkların da neden olduğu düşünülmektedir.

Araştırmanın öğretim elemanlarının mesleki eğitim verilen müzik eğitimi kurumlarında 20. yüzyıl genişletilmiş keman çalma tekniklerinin öğretim sürecine dahil olabilmesi konusundaki görüşleri nasıldır sorusuna yönelik olarak, Tablo 14'te gösterildiği üzere elde edilen bilgilere bakıldığında, öğretim sürecine dahil edilebilmesinin yeterli bulunmaması önceki sorularda verilen öğrenci profilinin yeterli bulunmaması görüşleriyle paralellik göstermektedir. Eğitim programlarının ağırlıklı olarak geleneksel tekniklerin 
öğretilmesine yönelik oluşunun bu konun yetersizliğine yol açan etkenlerden olduğunu düşündürmektedir.

Araştırmanın öğretim elemanlarının mesleki eğitim verilen müzik eğitimi kurumlarında 20. yüzyıl genişletilmiş keman çalma tekniklerinin öğretimi konusunda Türkiye'de yetişen keman eğitimcilerinin bilgi ve donanımlarını yeterli bulma durumu nasıldır sorusuna yönelik olarak, Tablo 15'de gösterildiği üzere, verilen cevaplara bakıldığında; keman eğitimcilerinin yetersiz bulunmasının bu konu üzerinde ayrıca çalışılması gerektiğine yönelik görüşler olduğunu ortaya çıkarmaktadır. Ayrıca önceki sorularda verilen bu konu ile ilgili özel uzmanların getirtilmesi ve çağdaş oda müziği gibi oluşumlarla başlatılması şeklindeki eğitmen görüşlerinin bulunması, bahsedilen ‘özel uzman’ ifadesinin genişletilmiş keman çalma teknikleri üzerine yoğunlaşmış eğitimcileri işaret ettiğini düşündürmektedir.

Genişletilmiş çalma teknikleriyle ilgili genel olarak bakıldığında ise bu tekniklerle ilgili farklı yaklaşım ve fikirler olduğu göze çarpmaktadır. Karcılığlu çalışmasında (2011, s. 130), "Çok ilginç olan bu yenilikler klasik çalış ve notasyonla yazılan eserleri ister istemez 'modası geçmiş’ eskiye aittir yaftalarının yapıştırılmasına sebep olur. Genişletilmiş çalgı tekniklerin aslında modası geçmiştir. Günümüzde genci yaşlısıyla bir çok besteci geleneksel çalış ve notalama şekline dönüş yapmış. Bu sistemden vazgeçmiştir” şeklinde bahsetmekte, bunun yanında Knox (2018, s. 8), “bu tekniklerle ilgili deneyim eksikliğinden dolayı, birçok çalgıcı bu tekniklerle üretilen sesleri manipüle etmek için gerekli estetik yargıdan yoksundur, bu da yeni eserlerin müzikal olarak tatmin edici olmayan performanslarına neden olur" şeklinde yaklaşmaktadır ve bu tekniklerin öğretilmesine ilişkin pedagojik stratejiler geliştirdiği bir çalışma yaptığı görülmektedir.

\section{Öneriler}

Eğitimenlerin konu ile ilgili yaklaşımlarının sağlıklı bir şekilde değerlendirilebilmesi ve ileriye yönelik çalışmalar yapılabilmesi adına, Türkiye'de eğitimde kullanım durumunun ortaya konulması ve bundan sonraki çalışmaların belirlenen bu zemin üzerinden yürütülmesinin alana katkı sağlayacağı düşünülmektedir.

Genişletilmiş keman çalma teknikleri ile ilgili alanda yapılmış çalışmaların az olduğu ve kaynakların genellikle yabancı olduğu görülmektedir. Bu konudaki çalışmaların çoğaltılmasının alana sağlayacağı katkıdan dolayı araştırmacılara bu konu ile ilgili çalışmalar yapmaları, bestecilere bu tekniklerin öğretimine yönelik eserler bestelemeleri önerilmektedir. 
Türkiye'de, günümüzde genişletilmiş çalma teknikleri ile ilgili çalışmalar yapan besteciler bulunmaktadır. Bu alanda yapılacak çalışmaların tekniklerin kullanımı ve bu eserlerin seslendirilmesine sağlayacağı katkı açısından bestecilerle veya teori eğitmenleriyle birlikte yürütülmesi önerilmektedir.

Genişletilmiş keman çalma teknikleriyle bağlantılı olarak notasyon ve farklı yazım tekniklerinin yanında, ses yükselticiler, elektronik ve midi keman kullanımı gibi teknolojik gelişimlerin de incelenmesi araştırmacılara önerilmektedir.

Teşekkür: Çalışmaya görüşleriyle sağladığı katkıları nedeniyle sayın Doç. Dr. Ümit Kubilay Can’a, İngilizce çevirilerle sağladığı katkıları nedeniyle Billur Karayalçın'a teşekkür ederiz.

Hakem Değerlendirmesi: Dış bağımsız.

Çıkar Çatışması: Yazarlar çıkar çatışması bildirmemiştir.

Finansal Destek: Yazarlar bu çalışma için finansal destek almadığını beyan etmiştir.

Peer-review: Externally peer-reviewed.

Conflict of Interest: The authors have no conflict of interest to declare.

Grant Support: The authors declared that this study has received no financial support.

\section{Kaynakça/References}

Arditti, I., ve Platz, R. HP. (2013). The techniques of violin playing. Basel: Music Akademie.

Biricik, S. B. (1998). Keman sağ el tekniğinin Galamian ve Rus okullarından örneklerle incelenmesi. (Yayımlanmamış Yüksek Lisans Tezi). İstanbul Üniversitesi Sosyal Bilimler Enstitüsü, İstanbul.

Danio, E. (2010). The double bass: A technical study of timbre. (Yayımlanmamış Doktora Tezi). University of Delaware, USA.

Ho, A. K. (2006). Technical demands of selected contemporary works for violin. (Yayımlanmamış Doktora Tezi). University of Tasmania, Australia.

Ishii, R. (2005). The development of extented piano techniques in twentieth-century American music. (Yayımlanmamış Doktora Tezi). Florida State University, USA.

Karasar, N. (2000). Bilimsel Araştırma Yöntemi. Ankara: Nobel Yayınevi.

Karcılığlu, İ. (2018). Yaylı çalgılarda kullanılan modern icra teknikleri ve grafik notasyonu. Konservatoryum, 5 (1), 19-38.

Karcılığlu, İ. (2011). 18. yüzyıl standart orkestra çalgılarının 20. yüzyılda genişletilmiş çalgı teknikleriyle kullanımı. (Yayımlanmamış Sanatta Yeterlik Tezi). İstanbul Üniversitesi Sosyal Bilimler Enstitüsü, İstanbul.

Knox, G. (2018). Stretching the string: Embedding pedagogical strategies in extended techniques compositions for strings. (Yayımlanmamış Doktora Tezi). Middlesex University, London.

Kollo, İ. M. (2016). 17. ve 18. yüzyılda keman çalma tekniklerinin gelişimi. (Yayınlanmamış Yüksek Lisans Tezi). Mersin Üniversitesi Güzel Sanatlar Enstitüsü, Mersin.

Merdinli, Ö. (1998). Keman sol el tekniğinin Galamian ve Rus okulundan örneklerle incelenmesi. (Yayınlanmamış Yüksek Lisans Tezi). İstanbul Üniversitesi Sosyal Bilimler Enstitüsü, İstanbul. 
Tischhauser, K. J. (2002). A survey of the use of extended techniques and their notations in twentieth century string quartets written since 1933 by American composers with a selected annotated bibliography and discography. (Yayımlanmamış Doktora Tezi). Florida State University, Florida.

Porta, E. (1985). The violin harmonics: classification and new techniques. Milano: G. Ricordi.

Sevsay, E. (2015). Orkestrasyon. İstanbul: Yapı Kredi Yayınları.

Stone, K. (1980). Music Notation in the twentieth century. New York: W. W. Norton.

Strange, P., ve Strange, A. (2001). The contemporary violin: extended performance technique. USA: University of California.

Ulucan, S. (2005). Kemanda yay tekniğinin temel bilgileri ve gelişimi. (Yayınlanmamış Yüksek Lisans Tezi). İstanbul Üniversitesi Sosyal Bilimler Enstitüsü, İstanbul.

Vincent, M. (2003). Contemporary violin techniques: The timbral revolution. Yayımlanmamış ders notu. Academia Akademik Platformu. Erişim adresi: https://www.academia.edu/3257395/Contemporary_Violin_Techniques 
